\title{
Reconceptualizing the Classroom: An Immersive Digital Primary Source Exercise During COVID-19
}

\author{
Melinda McPeek, Jennifer Piegols, lan Post
}

\begin{abstract}
The Nabb Research Center for Delmarva History and Culture is part of Salisbury University Libraries and serves as a campus humanities research laboratory. With the closure of the university campus in March 2020 due to the COVID-19 pandemic, staff and faculty quickly transitioned to online instruction. In response, Nabb Center staff developed a digital primary source exercise that enabled students to engage with our collections in a meaningful way and explore the interconnectedness of archival materials and museum objects. This assignment unexpectedly presented our organization with new opportunities to expand our engagement within the university and broader community and will have a lasting impact on our instruction beyond the pandemic that prompted its creation.
\end{abstract}

The Nabb Research Center for Delmarva History and Culture at Salisbury University Libraries serves as a campus humanities research laboratory and collects and exhibits artefacts that bring to life the region's history and culture. Each year thousands of students and members of the public participate in Nabb Center classes, conduct research, visit exhibits, and attend our events. The campus is located on the rural Delmarva Peninsula, comprising the Eastern Shores of Maryland and Virginia and the southern part of Delaware. The region is characterized by a diverse population, relatively high rates of poverty, and a substantial number of jobs connected to agriculture and poultry production. The area is a hotspot for COVID-19, and the university has been greatly affected by the pandemic.

Before the pandemic, Nabb Center instruction typically involved hands-on primary source analyses and exercises utilizing a variety of materials. With the closure of campus in late March 2020, staff and faculty quickly transitioned to online instruction. Nabb Center staff sought creative ways to continue pedagogical support, recognizing the challenges with digital primary source instruction. These include limited archival literacy among students and the need to explain records decontextualized when rendered on digital platforms (Gormly et al. 2019). We will share one activity we initiated in response to the pandemic and discuss how it presented opportunities to expand our engagement with the university and broader community while challenging our students to confront difficult knowledge (Rose 2016). ${ }^{1}$

Prior to campus closure, the Nabb Center collaborated with an undergraduate environmental studies course (ENVR 305) with the theme of 'race and place'. Students examined the complexities of - and interactions between - the environment and communities of colour. In their first visit to the Nabb Center, students engaged with primary sources from local history archives related to racial segregation and became acquainted with archival and artefact collections. Two additional planned sessions at the Nabb Center were halted in response to the pandemic.

Working remotely, the course professor, curator, and local history archivist collaborated on merging the sessions' themes: analyzing primary source documents related to Chesapeake plantations and discussing exclusion, power, and privilege in cultural institutions (Golding 2016). We aimed for one interconnected project that aligned with the principles of Yakel and Torres' (2003) model for promoting archival intelligence. It would have to be completed 
remotely with digitized sources while engaging students in meaningful interactions with our collections. ${ }^{2}$ In addition, we hoped to incite students to draw parallels between past and present racial injustices.

During planning, one document that caught our attention was a 1767 family Bible that lists the names and ages of the ten children of Titus Pollitt, a man enslaved on a plantation near Fruitland, Maryland. In the same collection is an eighteenth-century mahogany secretary on display in our permanent exhibit. After tracing the secretary's provenance through estate inventories, we were able to link it directly to the plantation owner, Thomas Pollitt. These two objects presented possibilities for illustrating the intersection of our topics and formed the basis of a multi-part exercise utilizing digital primary and secondary sources that addressed race, the environment, and slavery.

Students first analyzed digitized documents related to enslaved and free black people on the Delmarva Peninsula, including a deed of manumission, evidence of title for a US Colored Troop volunteer who was enslaved, advertisements for runaway slaves and slave auctions, and a deed for a free black man's 1846 land purchase. Next, students responded to questions about how archival records document racial power structures and sanitize the institution of slavery. These questions were created in response to the Association of College and Research Libraries' Rare Book and Manuscript Section - Society of American Archivists (ACRL RBMS-SAA) Guidelines for Primary Source Literacy, ${ }^{3}$ part of which advances the ability to 'identify, interrogate, and consider the reasons for silences, gaps, contradictions, or evidence of power relationships in the documentary record.... 4

The second section of the project focused on slavery in the Pollitt family of Worcester County, Maryland. Students analyzed digital primary sources including the 1767 family Bible, a photograph of the secretary, and the estate inventory of Thomas Pollitt that lists both the desk and family members of enslaved people listed in the Bible. Students then reviewed 'Life of an Object', a section of the Princeton University online exhibit Ecology of an Exhibition that examines the creation, purpose, and use of an early nineteenth century silver sugar urn with an emphasis on its environmental impact, for instance, through silver mining and sugar production. ${ }^{5}$ Using the exhibit as a guide, students were asked to create a life cycle analysis for the Pollitt family secretary to explore the interconnections among this object, slavery, and the environment. To provide further historical context, students read 'Nature's Currency: the Atlantic Mahogany Trade and the Commodification of Nature in the Eighteenth Century' (Anderson 2004). The intent of the exercise was to encourage critical thinking about the interrelated social and environmental history of an object and perhaps yield different perspectives on the mahogany secretary.

The culmination of the project focused on having students examine the ways in which objects take on different meanings in a museum context. Students watched a video of Fred Wilson discussing his installations. ${ }^{6}$ In his groundbreaking 1992 exhibit Mining the Museum at the Maryland Historical Society, Wilson used techniques such as creating alternate labels and arranging and juxtaposing objects to question the validity of museums and highlight exclusions from the historic narrative. For example, Wilson displayed ornate silverware alongside slave shackles in a case labelled 'Metalwork 1793-1880' to call attention to how slavery contributed to the production of luxury goods (Corrin 2004).

We provided students with images of the secretary and its label as it appears in our permanent exhibit. It is currently displayed with other furnishings with an emphasis on its construction from a decorative arts perspective. Using Wilson's work as inspiration, students were asked to create a new label or suggest different ways in which the secretary from the $\mathrm{Nabb}$ Center collection might be displayed to create an alternative interpretation that highlights other aspects of the object explored in their life cycle analysis.

In the end, we developed a three-part project utilizing digital resources that replicated the classroom experience and allowed students to engage remotely with our collections. Even though the digital exercise originated as a rapid response to a shift due to COVID-19, it will become an integral part of the Nabb Center's instruction as our classes will be held exclusively online this fall.

Two positive and unexpected outcomes came from the digital Pollitt family exercise. After posting about the class assignment and sharing Pollitt family documents on our Facebook 
and Instagram pages, African-American descendants of the family offered to donate items to our collection. Publicizing the exercise and the story told by the documents thus helped us make new connections within our community and fill gaps within our collection. Additionally, the Nabb Center co-hosted a virtual summer institute for secondary school teachers focused on teaching with primary sources. ${ }^{7}$ The local history archivist and director recreated parts of the Pollitt exercise with the teachers, resulting in an insightful discussion about potential ambiguity in interpreting primary sources and the temptation to fill gaps in historical knowledge without proper documentation.

Responding to the needs created by the COVID-19 pandemic has provided us with the opportunity to expand our reach within the university and across Delmarva through new digital collections and virtual classroom activities. Although this pandemic has greatly affected how we provide educational instruction, it also instigated innovative avenues to digitally examine, interpret, and complicate the historical narrative, while promoting social justice awareness among students.

Received: 29 June 2020

Finally accepted: 19 August 2020

\section{Notes}

1 Rose is one example of the abundance of recent museum scholarship providing insights into teaching and interpreting difficult histories.

2 Yakel and Torres outline three dimensions that contribute to archival intelligence: "1) knowledge of archival theory, practices, and procedures; 2) strategies for reducing uncertainty and ambiguity when unstructured problems and ill-defined solutions are the norm; and 3) intellective skills'.

3 This section of the exercise, as well as the rest of the assignment, was guided by point 4D of the ACRL RBMS-SAA Joint Task Force on the Development of Guidelines for Primary Source Literacy, 'Guidelines for Primary Source Literacy - Final Version', 2018. https:// www2.archivists.org/sites/all/files/GuidelinesForPrimarySourceLiteracy-June2018.pdf, accessed 13 August 2020.

4 ACRL RBMS-SAA Joint Task Force on the Development of Guidelines for Primary Source Literacy (2018) 'Guidelines for Primary Source Literacy - Final Version', 2018, 5. https:// www2.archivists.org/sites/all/files/GuidelinesForPrimarySourceLiteracy-June2018.pdf, accessed 13 August 2020

5 Princeton University Art Museum, 'The Life of an Object', Ecology of an Exhibition, 2020. https://artmuseum.princeton.edu/ecologyofanexhibition/the-life-of-an-object, accessed 19 March 2020.

6 Pérez Art Museum Miami, 'Scholl Lecture Series: Fred Wilson', 2015. https://www.youtube. com/watch?v=-v2as0pNkog, accessed 12 March 2020.

7 Since 2017, the Nabb Center has partnered with Maryland Humanities, with funding through the Library of Congress' Teaching with Primary Sources Partner Program, to help secondary school teachers introduce primary sources using the National History Day model of project-based learning.

\section{References}

Anderson, J.L. (2004) 'Nature's Currency: The Atlantic Mahogany Trade and the Commodification of Nature in the Eighteenth Century', Early American Studies, 2 (1) 47-80. 
Corrin, L.G. (2004) 'Mining the Museum: An Installation Confronting History' in Gail Anderson (ed) Reinventing the Museum: Historical and Contemporary Perspectives on the Paradigm Shift, 248-57, Walnut Creek: Altamira Press.

Golding, V. (2016) Learning at the Museum Frontiers: Identity, Race and Power, London: Routledge.

Gormly, B., Seale, M., Alpert-Abrams, H., Gustavson, A., Kemp, A., Lindquist, T., and Logsdon, A. (2019) 'Teaching with Digital Primary Sources: Literacies, Finding and Evaluating, Citing, Ethics, and Existing Models', \#DLFteach, https://doi.org/10.2142 8/65a6243c.6b419f2b.

Rose, J. (2016). Interpreting Difficult History at Museums and Historic Sites, Lantham: Rowman \& Littlefield.

Yakel, E. and Torres, D.A. (2003) 'Al: Archival Intelligence and User Expertise', The American Archivist, 66 (1) 51-78.

\section{Authors}

\section{Melinda McPeek \\ mxmcpeek@salisbury.edu \\ https://www.salisbury.edu/libraries/nabb/}

Curator of Exhibits and Engagement

Edward H. Nabb Research Center for Delmarva History and Culture,

Salisbury University

United States

Principal contact for editorial correspondence.

mxmcpeek@salisbury.edu

Jennifer Piegols

ihpiegols@salisbury.edu

https://www.salisbury.edu/libraries/nabb/

University Archivist and Special Collections Librarian

Edward H. Nabb Research Center for Delmarva History and Culture,

Salisbury University

United States

\section{Ian Post}

impost@salisbury.edu

https://www.salisbury.edu/libraries/nabb/

Local History Archivist

Edward H. Nabb Research Center for Delmarva History and Culture,

Salisbury University

United States 